\title{
A review on the current condition and control of campus noise pollution in central region of China
}

\author{
Yang Ou ${ }^{1,3}$, Xiyan Zhang ${ }^{1,3}$, Lai Zhang ${ }^{1}$, and Songlin $\mathrm{Yu}^{1,2, *}$ \\ ${ }^{1}$ Hunan Provincial Key Lab of Dark Tea and Jin-Hua, Hunan City University, 413000 Yiyang, Hunan, People's Republic of China \\ ${ }^{2}$ School of Materials and Chemical Engineering, Hunan City University, 413000 Yiyang, Hunan, People's Republic of China \\ ${ }^{3}$ These authors contributed equally to this work.
}

\begin{abstract}
With the increasing public attention to environmental protection, the control of pollution has become a joint goal of human. As one of the four major environmental pollutions, noise pollution seriously affects the normal study, work and health of teachers and students in schools, hence becoming an environmental issue of general concern in modern society. At present, the research and prevention of noise in colleges and universities are still in the initial stage in China. In addition, there are few noise studies in universities based on regions. Most of people are lack of enough attention to noise pollution, prevention and control measures and there is much room for improvement in all aspects. The purpose of this review is to summarize the current situation and causes of campus noise pollution in the central region of China and put forward some suggestions to improve the quality of sound environment on campus. In the end, it will provide some feasible references for the research in related fields.
\end{abstract}

\section{Overview of domestic noise pollution research}

\subsection{Significance of research on campus noise in colleges and universities}

Noise pollution is a kind of invisible environmental pollution [1]. Its long-term harm is easy to be ignored by the public. The daily routine disturbed by noise on campuses cannot immediately return to normal with the disappearance of pollution sources. Jing Yang et al. proved that the noise (50dB (A) and above) had effects on the shifting, distribution, span and stability of attention [2]. If the noise pollution is getting worse, it may have a profound negative impact on teaching work and scientific research.

Through the combination of theoretical and practical data, the public can have a more intuitive understanding of the harm of noise pollution, so as to promote universities to prevent noise pollution and create a better campus environment for teachers and students.

\subsection{Present situation of campus noise in colleges and universities}

Having a more direct impact on daily life, noise pollution will lead to more complaints from residents [3]. In 2019, statistics from the "12369 Environmental Protection Reporting Platform" showed that reports related to noise accounted for $38.1 \%$ of the total, ranking second among all pollution factors [4]. Yue $\mathrm{He}$ et al. conducted noise monitoring in Chongqing Medical University and concluded that some areas had serious noise, which affected students' rest and attention [5]. Zhengyan He et al. conducted noise monitoring in South-Central University for Nationalities through the grid method and concluded that noise pollution inside and outside the campus has become a relatively common phenomenon [6].

The rapid development of economy promotes the popularization and development of education, and makes the population of college students expand constantly. The university students not only promote the economic development around the campus, but also produce various kinds of noise pollution. In the campus, the improvement of campus environment and quality of life is often accompanied by the generation of noise pollution, and the pollution has a more serious trend. Although most people are gradually aware of the harm of it, and domestic attention and research on campus noise are increasing, the monitoring technology and methods are not yet mature. There is no unified and standardized monitoring standards and methods, with large space for improvement.

\section{Examples of campus noise pollution in central universities}

\subsection{Introduction to the central region of China}

The central region is the key region of China's new industrialization, urbanization, informatization and

\footnotetext{
*Corresponding author: ys1_xy3@163.com
} 
agricultural modernization. By 2017, the land area and population of Shanxi, Anhui, Jiangxi, Henan, Hubei and Hunan (six provinces in the central region) accounted for $10.7 \%$ and $26.6 \%$ of the whole country respectively. It is the region with the most potential to form new growth poles, expand domestic demand and improve the level of opening up [7].

\subsection{Current situation of campus noise pollution in Shanxi Province}

Taiyuan University of Technology, which is a century-old institution of learning with a long history, profound deposits and distinctive features, is taken as an example to illustrate the acoustic environment of universities in Shanxi Province. Haijun Zhao et al. monitored and evaluated the acoustic environment of Yingxi campus of Taiyuan University of Technology with the method of questionnaire survey combined with fixed-point monitoring [8].

The fixed-point measurement method is quoted in Measuring Method of Environmental Noise of Urban Area (GB/T14623-93); the monitoring conditions and instruments meet the requirements of the national standard; the standard for the result evaluation is Environmental Quality Standard for Noise (GB3096-2008) [9-10]. The surveyors measures the sound environment in the main teaching buildings, the square in front of the library, the basketball court, the graduate dormitory and the main office buildings. The monitoring results are as follows (see Table 1-5).

Table 1. Acoustic environment measurement data sheet near the classroom (dB) [8]

\begin{tabular}{cccccccccc}
\hline location & time & $\mathbf{L}_{\mathbf{5}}$ & $\mathbf{L}_{\mathbf{1 0}}$ & $\mathbf{L}_{\mathbf{5 0}}$ & $\mathbf{L}_{\mathbf{8 0}}$ & $\mathbf{L}_{\mathbf{9 5}}$ & $\mathbf{L e q}$ & $\mathbf{L m a x}$ & $\mathbf{L m i n}$ \\
\hline \multirow{3}{*}{ classroom } & $\mathrm{am} 8: 30$ & 57.8 & 55.7 & 51.5 & 48.7 & 48.4 & 53.2 & 63.6 & 46.8 \\
\cline { 2 - 9 } & $\mathrm{am} \mathrm{11:05}$ & 59.8 & 58.1 & 53 & 49.3 & 48.4 & 56.5 & 77.7 & 47.5 \\
\cline { 2 - 9 } & $\mathrm{pm} \mathrm{15:30}$ & 60.7 & 59.5 & 52.4 & 49.4 & 48.9 & 63.3 & 72.2 & 46.9 \\
\cline { 2 - 9 } & $\mathrm{pm} \mathrm{17:10}$ & 58.2 & 56.7 & 52.1 & 49 & 47.9 & 54.4 & 75.2 & 47.1 \\
\hline
\end{tabular}

Table 2. Acoustic environment measurement data sheet near the square $(\mathrm{dB})$ [8]

\begin{tabular}{cccccccccc}
\hline location & time & $\mathbf{L}_{\mathbf{5}}$ & $\mathbf{L}_{\mathbf{1 0}}$ & $\mathbf{L}_{\mathbf{5 0}}$ & $\mathbf{L}_{\mathbf{8 0}}$ & $\mathbf{L}_{\mathbf{9 5}}$ & $\mathbf{L e q}$ & $\mathbf{L m a x}$ & Lmin \\
\hline \multirow{5}{*}{ square } & $\mathrm{am} \mathrm{9:00}$ & 58.2 & 56.4 & 51.8 & 49.1 & 48.6 & 54.5 & 74.1 & 47.7 \\
\cline { 2 - 9 } & $\mathrm{am} \mathrm{11:30}$ & 62.6 & 60.5 & 51.6 & 48 & 47.2 & 48.2 & 85.7 & 46 \\
\cline { 2 - 9 } & $\mathrm{pm} \mathrm{16:00}$ & 60.5 & 58.3 & 52.9 & 50.1 & 49.5 & 55.7 & 76.9 & 48.5 \\
\cline { 2 - 9 } & $\mathrm{pm} \mathrm{17:35}$ & 63.8 & 61.6 & 54.7 & 52 & 51.2 & 58.9 & 76.4 & 49.6 \\
\hline
\end{tabular}

Table 3. Acoustic environment measurement data sheet near the basketball court $(\mathrm{dB})$ [8]

\begin{tabular}{cccccccccc}
\hline location & time & $\mathbf{L}_{\mathbf{5}}$ & $\mathbf{L}_{\mathbf{1 0}}$ & $\mathbf{L}_{\mathbf{5 0}}$ & $\mathbf{L}_{\mathbf{8 0}}$ & $\mathbf{L}_{\mathbf{9 5}}$ & $\mathbf{L e q}$ & $\mathbf{L m a x}$ & Lmin \\
\hline & $\mathrm{am} \mathrm{9:30}$ & 72.2 & 69.8 & 62.7 & 59.2 & 57.7 & 65.4 & 82.2 & 55.9 \\
\cline { 2 - 9 } & noon 12:00 & 70 & 68.5 & 62.9 & 57.8 & 57 & 66.7 & 85.6 & 55.1 \\
\cline { 2 - 9 } $\begin{array}{c}\text { Basketball } \\
\text { court }\end{array}$ & $\mathrm{pm} \mathrm{16:28}$ & 68.8 & 66.8 & 52.5 & 59 & 58.3 & 64.5 & 77.6 & 56 \\
\cline { 2 - 9 } & $\mathrm{pm} \mathrm{17:59}$ & 70.1 & 68.9 & 64.5 & 61.4 & 61 & 66.7 & 79.8 & 59.1 \\
\hline
\end{tabular}

Table 4. Acoustic environment measurement data sheet near the postgraduate dormitory (dB) [8]

\begin{tabular}{cccccccccc}
\hline location & time & $\mathbf{L}_{\mathbf{5}}$ & $\mathbf{L}_{\mathbf{1 0}}$ & $\mathbf{L}_{\mathbf{5 0}}$ & $\mathbf{L}_{\mathbf{8 0}}$ & $\mathbf{L}_{\mathbf{9 5}}$ & $\mathbf{L e q}$ & $\mathbf{L m a x}$ & Lmin \\
\hline & $\mathrm{am} \mathrm{10:30}$ & 62 & 59.5 & 55.6 & 53.5 & 52.5 & 58.5 & 72.4 & 51.3 \\
\cline { 2 - 10 } & $\mathrm{noon} \mathrm{12:24}$ & 64.1 & 62.2 & 57 & 55 & 54.5 & 60 & 73.7 & 53.7 \\
\cline { 2 - 10 } $\begin{array}{c}\text { Postgraduate } \\
\text { Dormitory }\end{array}$ & $\mathrm{pm} \mathrm{16:45}$ & 64.8 & 62.2 & 56.7 & 54.3 & 53.8 & 59.3 & 73.8 & 52.6 \\
\cline { 2 - 10 } & $\mathrm{pm} \mathrm{18:20}$ & 63.6 & 62.4 & 57.7 & 55.7 & 55.4 & 59.7 & 75.2 & 54.8 \\
\hline
\end{tabular}


Table 5. Acoustic environment measurement data sheet in front of the main office $(\mathrm{dB})[8]$

\begin{tabular}{cccccccccc}
\hline location & time & $\mathbf{L}_{\mathbf{5}}$ & $\mathbf{L}_{\mathbf{1 0}}$ & $\mathbf{L}_{\mathbf{5 0}}$ & $\mathbf{L}_{\mathbf{8 0}}$ & $\mathbf{L}_{\mathbf{9 5}}$ & $\mathbf{L e q}$ & $\mathbf{L m a x}$ & Lmin \\
\hline \multirow{3}{*}{$\begin{array}{c}\text { In front of } \\
\text { the main } \\
\begin{array}{c}\text { office } \\
\text { building }\end{array}\end{array}$} & $\mathrm{am} \mathrm{10:45}$ & 63.4 & 61.2 & 55 & 56 & 55.3 & 61 & 74.1 & 53.7 \\
\cline { 2 - 10 } & $\mathrm{pm} \mathrm{13:00}$ & 64.7 & 62.4 & 58 & 58 & 56.5 & 63 & 74.7 & 54.7 \\
\cline { 2 - 10 } & $\mathrm{pm} \mathrm{16:58}$ & 64.9 & 62.3 & 58.1 & 55.3 & 56.8 & 61.3 & 75 & 53.6 \\
\hline
\end{tabular}

The researchers randomly conducted a questionnaire survey among more than 200 teachers and students on campus, and 170 valid questionnaires were collected. $63 \%$ of the respondents think that the overall sound environment on campus is good. They generally believe that the sound environment on campus is suitable for teachers and students to carry out normal study and work. However, $50 \%$ of the respondents also think that it still needs to be improved. It is generally accepted that the main sources of noise are traffic transportation, construction and social life noise.

Based on the monitoring data and questionnaire survey, the characteristics of acoustic environment of Taiyuan University of Technology are summarized as follows:

1) The school has taken a series of measures to reduce the traffic noise and got some results. However, the overall sound environment quality is still poor, and there is much room for improvement in the noise of social life.

2) The noise of most points continues to exceed the standard, and only a few points reach the standard at a few times; man-made noise is the main cause, such as noise caused by doing sports.

3) The results of the questionnaire survey show that $36.5 \%$ of the respondents think that the quality of sound environment on campus is average. More than half of those surveyed think that the measures taken to prevent and control noise pollution are not enough.

\subsection{Current situation of campus noise pollution in Anhui Province}

Hefei University of Technology (HEUT), located in Hefei, Anhui Province, is a key university belonging to administration of the Ministry of Education of China. This paper takes it as an example to illustrate the acoustic environment status in universities in Anhui Province. Chaojun Ge et al. used the census monitoring method in GB3096-2008 to carry out noise monitoring on the south campus of HEUT. The measurement conditions and measuring instruments were in line with the requirements of GB3096-2008, and the measured data were directly used to analyze the acoustic environment of the campus [11].

The south campus of HEUT is classified as a first-class area according to the GB3096-2008 standard. Through the monitoring, it can be preliminarily obtained that more than $70 \%$ of the area in the south campus exceeds the standard of noise at night, while $14.6 \%$ of the area in the daytime exceeds the standard of noise
(Fig.1-4).

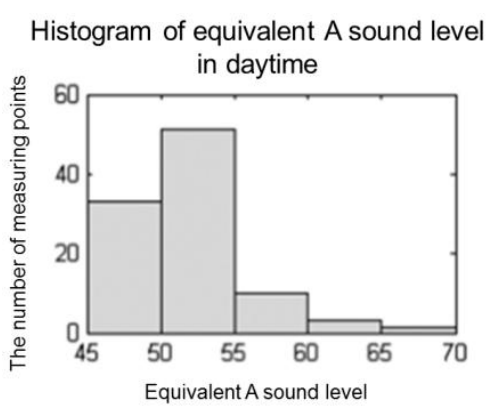

Fig. 1. Sound level distribution map (in daytime), dB(A) [11]

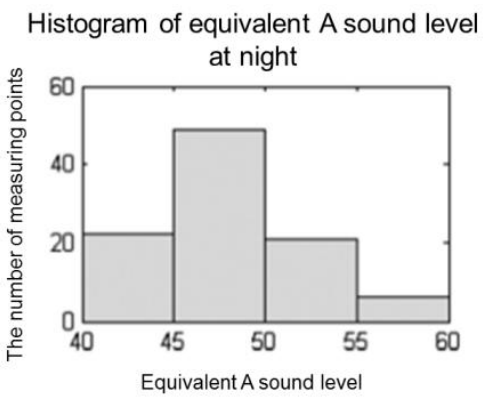

Fig. 2. Sound level distribution map (at night), dB(A) [11]

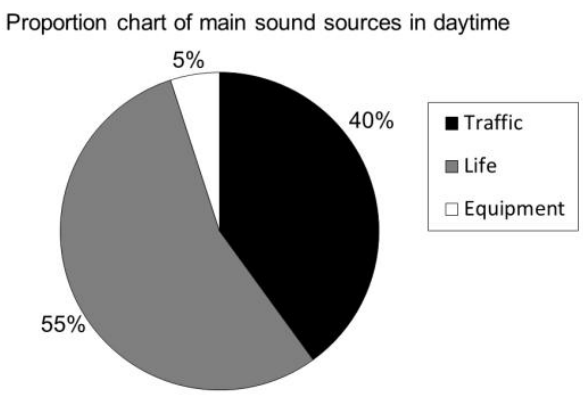

Fig. 3. Source ratio diagram (in daytime) [11]

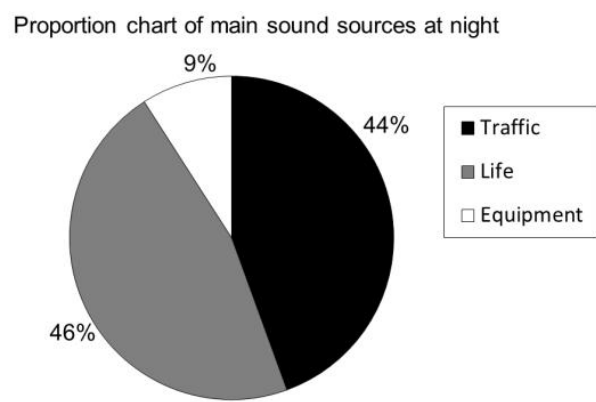

Fig. 4. Source ratio diagram (at night) [11]

We can get a result from the synthesis of above data: 
1) In general, the acoustic environment level in the daytime is basically up to standard, but the overall acoustic environment level in the night exceeds the standard [11].

2) The difference of measuring points at night was generally greater than that at daytime, while daytime acoustic environment is more stable than that at night. There may be more sudden noise pollution at night.

3) The main noise sources between day and night are traffic noise (more than 40\%) and noise caused by people's talking.

\subsection{Current situation of campus noise pollution in Jiangxi Province}

Shangrao Normal University is chosen as the representative to learn about the current situation of noise pollution in colleges and universities in Jiangxi Province. Weihua Chen et al. set up 6 monitoring areas there according to different functional areas, and obtain the monitoring results after continuous monitoring for seven days (see Table 6) [12].

Table 6. Leq average value and noise source of each measuring point at different time (dB)

\begin{tabular}{lcccc}
\hline \multirow{2}{*}{ Measuring point } & \multicolumn{3}{c}{ time } & Noise source \\
\cline { 2 - 4 } Dormitory area & a.m. & p.m. & at night & Talking and music, vehicles honking \\
\hline Basketball court area & 51.73 & 52.06 & 56.19 & Thement noise \\
\hline Football field & 58.76 & 63.54 & 52.67 & Movemen \\
\hline Staff accommodation area & 50.31 & 64.74 & 50.67 & Movement noise \\
\hline Old dormitory-main building area & 50.73 & 51.13 & 50.98 & vehicles honking, Pedestrian voice \\
\hline School gate & 65.21 & 54.03 & 50.26 & Conversation noise \\
\hline
\end{tabular}

According to GB3096-2008, we shall classify Shangrao Normal University into the first-class standard. Referring to the monitoring data, it can be seen that the area of daytime noise exceeding standard is mainly in the sport areas and most of it is concentrated in the afternoon; the areas exceeding the standard at night almost cover the whole monitoring area, and the noise pollution in the dormitory area is particularly serious because students are concentrated in the dormitory at night.

Based on the above monitoring results, the following characteristics of noise pollution in Shangrao Normal University are summarized:

1) Daytime noise pollution is mainly concentrated in the sport areas in the afternoon, and night noise pollution is mainly concentrated in the dormitory area

2) From the point of view of noise pollution inside and outside the school, the inside is obviously better than the outside, mainly because of the large traffic flow outside the campus and the serious traffic noise pollution.

\subsection{Current situation of campus noise pollution in Henan Province}

Henan University (HNU) is a university jointly established by the government of Henan Province and the Ministry of Education. This paper makes use of its acoustic environment to learn about the situation of the acoustic environment of universities in Henan Province. In accordance with the provisions of GB3096-2008, Nan Wang et al. monitored and evaluated the acoustic environment of Jinming campus of HNU and the traffic noise of three surrounding roads by using grid measurement method [13].

The whole campus is divided into 108 grids, and the central point is set as the monitoring point. The monitoring instruments and conditions meet the requirements of GB3096-2008. The results are shown in the chart below (see Table 7).

Table 7. Traffic noise Leq [13]

\begin{tabular}{cccccccccccc}
\hline road & \multicolumn{10}{c}{ Leq/dB } \\
\hline \multirow{2}{*}{$1 \#$} & day & 65.7 & 64.6 & 63.4 & 63.0 & 62.8 & 62.3 & 62.3 & 61.8 & 61.4 & 60.7 \\
\cline { 2 - 11 } & night & 60.6 & 60.6 & 60.6 & 59.5 & 58.8 & 58.8 & 58.4 & 58.3 & 57.5 & 57.4 \\
\hline \multirow{2}{*}{$2 \#$} & day & 71.2 & 71.0 & 70.2 & 70.1 & 69.8 & 68.8 & 68.8 & 68.2 & 68.2 & 67.9 \\
\cline { 2 - 11 } & night & $67 . .2$ & 68.0 & 68.0 & 67.9 & 66.0 & 65.7 & 65.7 & 65.6 & 65.5 & 64.7 \\
\hline \multirow{2}{*}{$3 \#$} & day & 67.9 & 66.6 & 66.4 & 66.2 & 65.8 & 65.7 & 65.2 & 65.2 & 65.1 & 64.7 \\
\cline { 2 - 12 } & night & 66.2 & 65.7 & 65.6 & 65.5 & 65.3 & 65.1 & 64.8 & 64.8 & 64.6 & 63.7 \\
\hline
\end{tabular}

Note: 1\# represents Jinming Avenue, 2\# represents Tokyo Avenue, and 3\# represents Yishan Avenue

According to the charts, the acoustic environment characteristics of Jinming campus of HNU are as 
follows:

1) The quality of daytime acoustic environment is lower than that of night acoustic environment, which is caused by more activities of teachers and students in daytime.

2) The stability of the acoustic environment at night is not as good as that in the daytime. This is because the noise is less at night, and the sound environment is easy to be damaged, resulting in great fluctuation.

3) In daytime, the acoustic environment of Jinming Avenue and Yishan Avenue were better, and only the noise rate of Tokyo Avenue exceeded 20\%. At night, the noise of the monitoring points on the three main roads exceeds the standard, and seriously affects the normal rest of the students in the student apartments on the adjacent roads.

\subsection{Current situation of campus noise pollution in Hubei Province}

Central China Normal University, which is a key comprehensive normal university directly under the Ministry of Education, is located in Wuhan, Hubei Province. Haoran Qiu et al. divided its campus into 12 uniform grids to monitor the distribution points by using the network partition method. The overall evaluation of the campus environment was carried out by calculating Leq and referring to Environmental Quality Standard for Noise (GB3095-2008). The monitoring results are shown in the Table 8 [14].

Table 8. Monitoring values of campus noise monitoring points

\begin{tabular}{|c|c|c|c|c|c|c|c|c|}
\hline \multirow{2}{*}{ Monitoring points } & \multicolumn{4}{|c|}{ day } & \multicolumn{4}{|c|}{ night } \\
\hline & LAep & $\mathbf{L}_{10}$ & $\mathbf{L}_{50}$ & $\mathbf{L}_{90}$ & LAep & $\mathbf{L}_{10}$ & L50 & L90 \\
\hline 1. Guojiao Building 4 & 66.2 & 71.5 & 63.5 & 58.8 & 57.4 & 60.8 & 56.7 & 54.4 \\
\hline 2. Liberal Arts Teaching and Research Complex & 63.3 & 68.2 & 60.1 & 54.4 & 51.8 & 54.7 & 50.9 & 47.2 \\
\hline 3. library & 64.2 & 68.1 & 63.6 & 61.9 & 54.7 & 58.3 & 54.1 & 52.1 \\
\hline 4. Guixiangyuan Canteen & 71.5 & 73.4 & 71.3 & 69.9 & 53.1 & 56.6 & 52.5 & 50.7 \\
\hline 5. Administration Building & 60.1 & 64.2 & 58.1 & 53.2 & 47.4 & 50.7 & 46.6 & 43.6 \\
\hline 6. Boya Plaza & 78.7 & 79.2 & 76.9 & 68.9 & 54.5 & 54.1 & 53.1 & 44.8 \\
\hline 7. swimming pool & 65.2 & 70.7 & 63.0 & 59.1 & 53.2 & 57.4 & 51.1 & 46.3 \\
\hline 8. Youming Stadium & 72.6 & 75.4 & 66.0 & 55.5 & 52.1 & 54.7 & 51.7 & 49.9 \\
\hline 9. East District 6 & 69.1 & 73.7 & 64.8 & 57.7 & 54.4 & 57.3 & 53.7 & 50.6 \\
\hline 10. Qinyuanchun Canteen & 73.2 & 76.9 & 71.6 & 67.1 & 54.9 & 58.1 & 53.5 & 49.0 \\
\hline 11. Yuan Baoshan Building 4 & 64.7 & 69.7 & 62.5 & 58.2 & 54.6 & 60.0 & 53.5 & 51.9 \\
\hline 12. Higher Vocational Stadium & 83.6 & 85.2 & 82.5 & 77.2 & 52.7 & 56.4 & 51.8 & 49.1 \\
\hline
\end{tabular}

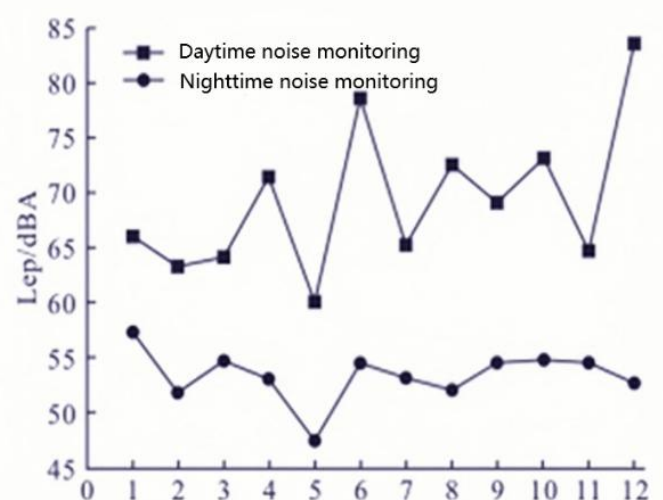

Fig. 5. Environmental Noise Monitoring Distribution [14]

From the chart, we can summarize the characteristics of acoustic environment of Central China Normal University:

1) The noise pollution is more serious in the daytime, mainly because the rain and pollution diversion projects in the school are concentrated in the morning during the monitoring period, and the activities of teachers and students are large in the daytime, so the noise exceeds the standard relatively high. At night, most construction projects are shut down, teachers and students go to bed, and the noise exceedance rate is relatively low (Fig.5).

2) As can be seen from Figure 3, the statistical data of each monitoring point fluctuate irregularly, and the frequency of fluctuation in day is higher than that in night. It can also be proved that noise pollution is more serious in the daytime than at night.

3) In addition, some uncertain factors could also lead to noise exceeding in some areas. For example: some students go to the piano store in Guojiao Building 4 to practice the piano, so in some periods, the noise exceeding rate in this area will increase; Guixiangyuan canteen provides catering services for most students in the western area, so the dining time will also have a rapid increase in the noise exceeding standard rate; the liberal arts teaching and research complex building is located in 
the open road section of the campus, so vehicles will pass randomly in this road section, resulting in a slight increase in the noise exceeding rate.

\subsection{Current situation of campus noise pollution in Hunan Province}

This paper takes Hunan University of Technology in
Zhuzhou city of Hunan Province as an example to introduce the present situation of campus noise pollution in Hunan Province. Jianlong Liu et al. adopted the method of combining questionnaire survey with actual monitoring, and carried out monitoring according to the methods in GB/T14623-1993. The monitoring equipment and conditions met the requirements, and the monitoring results are shown in the Table 9 [15].

Table 9. The daily average Leq measurement results of each measurement point on the campus at different times

\begin{tabular}{|c|c|c|c|c|}
\hline $\begin{array}{l}\text { Measuring } \\
\text { number }\end{array}$ & Measuring point name & Main sound source & $\begin{array}{c}\text { Day } \\
/ \mathrm{dB}(\mathrm{A})\end{array}$ & $\begin{array}{r}\text { Night } \\
/ \mathrm{dB}(\mathrm{A})\end{array}$ \\
\hline Measuring point $\mathrm{A}$ & Five buildings & $\begin{array}{l}\text { Motion noise, Building Construction, } \\
\text { Conversation }\end{array}$ & 61.31 & 61.05 \\
\hline Measuring point $\mathrm{B}$ & $\begin{array}{l}\text { 17th Building (in front } \\
\text { of the school hospital) }\end{array}$ & $\begin{array}{c}\text { Traffic noise, Building Construction, } \\
\text { Staff noise }\end{array}$ & 66.10 & 53.95 \\
\hline Measuring point $\mathrm{C}$ & Public building & $\begin{array}{l}\text { Lectures sound, Inter-class } \\
\text { communication, Bird calling }\end{array}$ & 63.28 & 61.63 \\
\hline Measuring point $\mathrm{D}$ & Thirty Building & Building Construction, Traffic noise & 56.94 & 63.58 \\
\hline Measuring point $\mathrm{E}$ & Twenty six Building & $\begin{array}{l}\text { Motion noise, Business activity, } \\
\text { Canteen working noise }\end{array}$ & 59.99 & 60.90 \\
\hline
\end{tabular}

The research team distributed 500 questionnaires on campus, with 475 valid copies. Most students think that the dormitory noise comes from outdoor noise which are artificial noise and almost all hours of the day are affected.

The following conclusions are drawn from monitoring data and questionnaires:

1) On the whole, the acoustic environment quality of the university campus is $\mathrm{p}$. The noise environment in the campus basically exists the phenomenon of exceeding the standard, which affects the normal daily activities of teachers and students. Especially at night, the noise pollution is very serious.

2) Construction, traffic and human noise are the main reasons for the noise exceeding the standard.

3) The questionnaire survey shows that $36 \%$ of teachers and students think that noise pollution seriously affects their daily life; and $33 \%$ of them think that noise pollution in campus is too serious and its negative influence lasts almost all day.

\section{Summary of main points of controlling noise pollution in campuses}

\subsection{Control of construction noise}

Construction noise is a problem in almost all universities. For the reconstruction projects in different areas, the construction time should be reasonably arranged to stagger with the teaching time and students' rest time. The teachers and students affected by the construction can also be issued with earplugs, earmuffs or other noise reduction tools, in order to ensure the efficiency of the project and effectively reduce the noise generation. In addition, environmental protection and sound insulation construction materials can be used in the renovation or construction to further improve the acoustic environment of learning and living for teachers and students.

\subsection{Regulate traffic control to reduce traffic noise}

The speed is the main factor that affects the noise of the car in the process of running. The faster the vehicle speed is, the greater the noise generated by the car engine and by the friction between the road and the car tire is. Therefore, it is necessary to perfect the traffic management system inside the campuses. Measures can be taken to limit the speed of cars on campuses and strictly prohibit honking to reduce noise. Besides, it is necessary to reasonably plan the parking lots on campuses, so as to avoid the unnecessary noise caused by car owners driving through for looking for parking spaces.

In the busy streets around the campus, it is suggested that the municipal departments should use low-noise materials to lay the roads as far as possible in order to reduce the noise in these sections. In the area close to the subway station, the noise of the subway should be mainly controlled. It is suggested to carry out some sound absorption or insulation treatment near the subway station, such as setting sound barriers similar to those on both sides of the high-speed railway tracks to alleviate traffic noise pollution. The location of main roads on campus should control the honking of cars and motorcycles, and the method of adding warning signs can be adopted.

\subsection{Increase campus greening}

Although the green area of some campuses is sufficient, the height of vegetation is relatively single, which is not conducive to reducing noise pollution. The afforestation around the campuses can be strengthened and the plant level can be increased to form the community of high 
and low coordination of various tree species. Climbing plants and vines can also be planted in the outer wall and railings. Because these plants can scatter or absorb some sound, which means that they can play the role of sound absorption and noise reduction and improve the sound absorption function of the wall. This measure can be applied to peripheral areas of the campus to reduce the impact of traffic noise on these locations. The areas with mild noise condition can be temporarily ignored.

\subsection{Reinforce the educational publicity of noise pollution}

The school should strengthen the publicity of jointly safeguarding the acoustic environment, emphasize the harm of noise, and carry out publicity and education from the perspective of groups. It can also organize students in the student union to distribute publicity leaflets for popularization of noise pollution, so as to improve students' public moral awareness and make students spontaneously reduce the noise emitted in the dormitory area during rest time. Publize teachers with the help of staff meetings, for example, remind teachers not to whistle when driving and try to close the front and back doors when teaching to reduce the disturbance to neighboring classrooms. Through the above measures to improve the noise prevention awareness of all teachers and students; At the same time, we should strengthen quality-oriented education and jointly build a "silent campus".

\subsection{Optimize daily management}

If the logistic teams are well educated about noise hazards, they can also better reduce the noise in campuses, because the staffs serve in all areas of the schools and can detect and discourage most of the man-made noise in time. The time and place of large-scale outdoor activities on campuses should be controlled. In principle, these activities should be far away from the teaching area and avoid the rest time of teachers and students to ensure the learning efficiency and rest quality of people. It is also very important to set up noise monitoring instruments to monitor the campus noise at night in real time, which can prevent and control the campus noise at night in time and create a more pleasant rest environment.

\subsection{Clear functional zoning}

The school should reasonably plan the functional area and carry out the construction of isolation zone. Each area of campus should be divided into corresponding functional areas according to its role in campus teaching, work and life. And greenbelts should be planted around each functional area according to the functions, and isolation belts of a certain width and a certain level should be established to achieve the effect of noise reduction, so as to avoid mutual interference between each functional area.

\subsection{Reasonable control of perimeter activities}

There are many recreational activities around most colleges and universities, and the phenomenon of street occupation is serious. Schools can coordinate with relevant departments to strengthen the standardized management of recreational activities around the campuses, so as to reduce the noise pollution to a certain extent.

\section{Summary and outlook}

Through the understanding of the monitoring situation of noise pollution in these six universities, the authors deeply realize that noise pollution has become a more and more common social problem around us. With the vigorous development of China's economy, the development of entertainment activities has also shown a good trend. As one of the main consumption forces of the entertainment industry, college students are bound to make the campuses and the surroundings the best choice for investors in the entertainment industry, which undoubtedly greatly aggravates the generation of campus noise. Therefore, the guidance and educational role of the school is particularly important. How to prevent noise pollution and ensure the normal study, work and life of teachers and students while maintaining economic development is a problem that needs to be carefully considered and properly solved.

Moreover, in different schools, the monitoring methods, the reference basis or the monitoring instruments are different, which also makes the comparability between different schools reduced. Based on this situation, the writer believes that it is very necessary to establish a unified monitoring means, methods and basis.

In addition to the conventional measures outlined above, we would also like to see the emergence of more pollution prevention measures that utilize the Internet + model. For instance, the establishment of a nationwide network of acoustic environment monitoring and exchange platform for colleges and universities can not only help us intuitively understand the current situation of pollution, but also facilitate better communication between colleges and universities on prevention and treatment. Whether the birth of $5 \mathrm{G}$ network will have a new collision with our noise pollution prevention and control, forming a win-win situation, is very anticipated.

All in all, noise pollution prevention and control is still in the beginning stage. It is hoped that in universities and colleges where new ideas, methods, and technologies are constantly emerging, teachers and students can work together to make more progress.

\section{Acknowledgments}

This work was supported by the Natural Science Foundation of Hunan Province (2020JJ5873) to Dr. Songlin $\mathrm{Yu}$. 


\section{References}

[1] L.L. Zhang, H. Cui, 2007, The Control and Analysis of the Campus Sound Environment, Journal of Henan Institute of Science and Technology, 35, 04, 36-38. (In Chinese)

[2] J. Yang, B.Y. Liu, L. Ling, Z.J. Li, X.H. Shao, Y. Tang, 2014, Effect of Noise on College Students' Attention, Journal of Environmental and Occupational Medicine, 31, 02, 119-121+125. (In Chinese)

[3] Z.W. Ba, J.B. Zhao, 2012, Environment Noise Monitoring and Evaluation of Binzhou University Campus, Heilongjiang Agricultural Sciences, 07, 98-102. (In Chinese)

[4] Ministry of Ecology and Environment of the People's Republic of China, 2019, China Environmental Noise Pollution Prevention and Control Report (In Chinese)

[5] Y. He, M.H. Chen, 2017, Environmental Noise Monitoring and Evaluation on the Campus of a Medical University, Journal of Green Science and Technology, 22, 62-64+67. (In Chinese)

[6] Z.Y. He, M.H. Mi, S.Y. Wei, M. Wu, J. Qu, Z.G. Xu, 2020, Measurement and evaluation of campus environment noise, LABORATORY SCIENCE, 23, 06, 13-18+22. (In Chinese)

[7] Y.W. Han, 2019, Accelerate the full rise of the Midlands, Globalization, 02, 19-23+134. (In Chinese)

[8] H.J. Zhao, 2012, Study on Accoustic Environment in University Campus-Taiyuan Yingxi Campus as an example, Unpublished, $\mathrm{PhD}$ dissertation, Taiyuan University of Technology. (In Chinese)

[9] State Environmental Protection Administration, 1994, Measuring method of environmental noise of urban area (GB/T14623-93). (In Chinese)

[10] Ministry of Environmental Protection of the People's Republic of China, General Administration of Quality Supervision, Inspection and Quarantine of the People's Republic of China, 2008, Environmental quality standard for noise (GB 3096-2008). (In Chinese)

[11] Z.J. Ge, 2014, Acoustic environment evaluation and related research on campus of Hefei University of Technology, Technology Innovation and Application, 23, 154-155. (In Chinese)

[12] W.H. Chen, B.Y. Wu, 2015, Noise Measurement and Evaluation in Shangrao Normal University, Jiangxi Chemical Industry, 05, 59-60. (In Chinese)

[13] N. Wang, X. Gao, L. Zhang, 2020, Monitoring and evaluation of environmental noise in Henan University, Resources Economization \& Environmental Protection, 01, 46-47. (In Chinese)

[14] H.R. Qiu, Y. Jiang, 2020, Monitoring and Evaluation of Campus Environmental Noise Taking Huazhong Normal University as An Example, Journal of Green Science and Technology,
06, 102-105. (In Chinese)

[15] J.L. Liu, F.Y. Yin, Y. Xiao, Z.Z. Pan, S.L. Zhang, P.Y. Fan, P. Liu, 2016, Studies on the Campus Environmental Noise of a University in Hunan Province, Building Energy \& Environment, 35, 02, 88-91. (In Chinese) 